\title{
Depletion of histone methyltransferase KMT9 inhibits lung cancer cell proliferation by inducing non-apoptotic cell death
}

Hannah Maria Baumert ${ }^{1}$, Eric Metzger ${ }^{1}$, Matthias Fahrner ${ }^{2,3,4}$, Julie George ${ }^{5}$, Roman K. Thomas ${ }^{5,6,7}$, Oliver Schilling $2,8,9$ and Roland Schüle $1,8,9,10,11^{*}$ (D)

\begin{abstract}
Background: Lung cancer is the leading cause of cancer related death worldwide. Over the past 15 years no major improvement of survival rates could be accomplished. The recently discovered histone methyltransferase KMT9 that acts as epigenetic regulator of prostate tumor growth has now raised hopes of enabling new cancer therapies. In this study, we aimed to identify the function of KMT9 in lung cancer.
\end{abstract}

Methods: We unraveled the KMT9 transcriptome and proteome in A549 lung adenocarcinoma cells using RNA-Seq and mass spectrometry and linked them with functional cell culture, real-time proliferation and flow cytometry assays.

Results: We show that KMT9a and - $\beta$ subunits of KMT9 are expressed in lung cancer tissue and cell lines. Importantly, high levels of KMT9a correlate with poor patient survival. We identified 460 genes that are deregulated at the RNA and protein level upon knock-down of KMT9a in A549 cells. These genes cluster with proliferation, cell cycle and cell death gene sets as well as with subcellular organelles in gene ontology analysis. Knock-down of KMT9a inhibits lung cancer cell proliferation and induces non-apoptotic cell death in A549 cells.

Conclusions: The novel histone methyltransferase KMT9 is crucial for proliferation and survival of lung cancer cells harboring various mutations. Small molecule inhibitors targeting KMT9 therefore should be further examined as potential milestones in modern epigenetic lung cancer therapy.

Keywords: Lung cancer, Non-small cell lung cancer, A549, Epigenetics, Histone methyltransferase, KMT9, Transcriptomics, Proteomics

\section{Background}

Lung cancer is the leading cause of cancer related deaths worldwide with 1.8 million deaths predicted for 2018 [1]. Treatment and prognosis widely vary between patients with aggressive small cell lung cancer and slower progressing non-small cell lung cancer (NSCLC). Non-small cell lung cancer represents $85 \%$ of all lung cancers, with

\footnotetext{
${ }^{*}$ Correspondence: Roland.schuele@uniklinik-freiburg.de

1 Klinik für Urologie und Zentrale Klinische Forschung, Medizinische

Fakultät, Albert-Ludwigs-Universität Freiburg, Universitätsklinikum Freiburg, Freiburg, Germany

Full list of author information is available at the end of the article
}

the most prominent subtypes being adenocarcinoma and squamous cell carcinoma. Yet, the 5-year survival rate for patients with lung cancer is only $10-20 \%$. New treatment strategies based on deeper understanding of the mechanisms driving a lung cell into malignancy are highly needed.

The discovery of global DNA hypo-methylation in human tumors initially broad epigenetics into the focus of cancer research and today epigenetic alterations are known to contribute to cancer development alongside to genetic mutations [2,3]. The concept of epigenetics was defined as inheritable changes in gene expression

c) The Author(s) 2020. This article is licensed under a Creative Commons Attribution 4.0 International License, which permits use, sharing, adaptation, distribution and reproduction in any medium or format, as long as you give appropriate credit to the original author(s) and the source, provide a link to the Creative Commons licence, and indicate if changes were made. The images or other third party material in this article are included in the article's Creative Commons licence, unless indicated otherwise in a credit line to the material. If material is not included in the article's Creative Commons licence and your intended use is not permitted by statutory regulation or exceeds the permitted use, you will need to obtain permission directly from the copyright holder. To view a copy of this licence, visit http://creativeco mmons.org/licenses/by/4.0/. The Creative Commons Public Domain Dedication waiver (http://creativecommons.org/publicdomain/ zero/1.0/) applies to the data made available in this article, unless otherwise stated in a credit line to the data. 
that are not due to any alteration in the DNA sequence and relies on DNA methylation and post-translational histone modifications. The modifications can then recruit effector molecules and chromatin modifiers to alter gene expression patterns $[4,5]$. The most abundant histone modifications are acetylation, phosphorylation, ubiquitination and methylation by specific chromatin-modifying enzymes. Writing of methyl marks on lysine residues of histone proteins is performed by histone lysine methyl transferases, of which nine were described to be associated with lung cancer [6]. Until recently, all known histone lysine methyl transferases belonged to the su(var)3-9, enhancer-of-zeste and trithorax (SET) domain family with the only exception being DOT1L that belongs to the seven- $\beta$-strand family $[7,8]$. Recently, a second histone lysine methyl transferase of the seven- $\beta$-strand family named lysine methyl transferase 9 (KMT9) was described [9]. KMT9 is an heterodimeric enzyme formed by the assembly of KMT9 $\alpha$ (also known as C21ORF127, HEMK2 [10, 11], MTQ2, N6AMT1 [12], PRMC or PRED28 [13] and KMT9 $\beta$ (also known as TRMT112) [9]. KMT9 mono methylates lysine 12 of histone 4 (H4K12me1) in vitro and in vivo thereby controlling proliferation of prostate tumor cells. In prostate tumor cells, KMT9 was found enriched at promoters of numerous cell cycle regulators and it has been shown that KMT9 controls cell cycle progression. KMT9 depletion severely affects proliferation of androgen receptor-dependent as well as castration- and enzalutamide-resistant prostate cancer cells and xenograft tumors [9]. Yet, the function of KMT9 in lung cancer cells has remained elusive. In the present study, we aimed to characterize the role of the novel histone methyltransferase KMT9 in lung cancer.

\section{Methods}

\section{Cell culture}

A549 and PC-9 cells were cultured in DMEM. NCIH2087 and NCI-H82 cells were cultured in RPMI 1640. GLC-2 cells were cultured in RPMI 1640 supplemented with $1 \mathrm{mM}$ sodium pyruvate and $50 \mu \mathrm{M} 2$-mercaptoethanol. IMR-90 and CRL-7000 cells were cultured in EMEM. All media were supplemented with $10 \%$ foetal calf serum, penicillin/streptomycin, plasmocin and glutamine. Cells were cultured in plasmocin containing medium at all times and are mycoplasma-free. IMR-90 cells were obtained from ATCC. The other cell lines were kind gifts from research groups as follows: NCI-H82 from M. Burger, Freiburg; GLC-2 from R. Büttner, Bonn; A549 from M. Witzenrath, Berlin; PC-9 from L.C. Heukamp, Köln; NCI-H2087 from S. Wöhrle, Boehringer-Ingelheim.
Certificates of cell line authentication are provided as Additional files 1, 2, 3, 4, 5, 6, 7.

\section{Transfection with siRNA}

Cells were transfected with the indicated siRNAs in presence of DharmaFECT 1 (A549; Dharmacon) or RNAiMAX (GLC-2, PC-9, NCI-H2087; Life Technologies) according to the manufacturer's instruction with a final siRNA concentration of $65 \mathrm{nM}$ (DharmaFECT 1) or $50 \mathrm{nM}$ (RNAiMAX). The sequences of the siRNAs (Stealth RNAi ${ }^{\mathrm{TM}}$ siRNAs; Life Technologies) used in the experiments are as following: siControl: 5'-GAAAGU CCUAGAUCCACACGCAAAU- $3^{\prime}$; siKMT9 $\alpha \# 1$ : $5^{\prime}$-ACG CUGUAACAAAGUUCACAUUCAA- $3^{\prime}$; $\quad$ siKMT $9 \alpha \# 2$ : 5'-CACGCUGUAACAAAGUUCACAUUCA-3'.

\section{Western blot analysis}

Experiments were performed as previously described [14]. If not declared otherwise, 3 days before harvesting, cells were transfected with siRNA as indicated. The following antibodies were used: anti-KMT9 $\alpha$ (\#27630, lot 20062017, Schüle Lab), anti-KMT9ß (\#28358, lot 27022018, Schüle Lab), anti-H4K12me1 (\#27429, lot 27062017, Schüle Lab); anti-H4 (ab31830, lot GR3204774-2, abcam); anti-Tubulin (alpha tubulin, \#T6074, lot 03714804 V, Sigma), anti-LMNA (sc-20680, lot F2607, Santa Cruz); anti-GAPDH (MAB574, lot 3273148, R\&D systems); anti-SMARCA2 (NB100-55308; lot A1; Novus biologicals); anti-TIMP2 (CST\#5738, lot 3, Cell signaling); anti-SOD2 (CST\#13194, lot 1, Cell signaling); anti-YES1 (\#PA5-80243, lot VA2919193, Invitrogen). Proteins from patient tissues were extracted using the Minilys homogenizer (Bertin instruments) and RIPA buffer (1 mM EDTA, 50 mM Tris-HCL pH7.5, SDS 0.1\%, $\mathrm{NaCl} 150 \mathrm{mM}$, NP-40 1\%, Na deoxycholate 1\%, protease inhibitor cocktail EDTA-free). Samples were cycled for $15 \mathrm{~s}$ at top speed.

\section{Cellular fractionation}

For cellular fractionation, a modified REAP protocol [15] was used. Briefly, cell pellets obtained by scraping were washed in PBS and suspended in 0.1\% NP-40/PBS, spun down for $10 \mathrm{~s}$, and the supernatant was taken as cytosolic fraction. Pellets of the remaining nuclear fractions were washed with $0.1 \% \mathrm{NP}-40 / \mathrm{PBS}$, suspended in protein lysate buffer $(50 \mathrm{mM}$ Tris- $\mathrm{HCl}(\mathrm{pH} 8), 170 \mathrm{mM} \mathrm{NaCl}$, $0.1 \%$ NP-40, $0.2 \mathrm{mM}$ DTT, $20 \%$ glycerol, complete protease inhibitor EDTA-free (Roche), phosphatase inhibitor cocktail (Sigma)), kept on ice for $10 \mathrm{~min}$ and sonicated $90 \mathrm{~s}$. Protein concentrations were determined using Nanodrop ND-1000 (Thermo Fisher). $30 \mu \mathrm{g}$ cytosolic and 
$150 \mu \mathrm{g}$ nuclear extract were mixed with SDS-running buffer and denaturized $10 \mathrm{~min}$ at $99^{\circ} \mathrm{C}$. The samples were then loaded onto a $15 \%$ acrylamide gel for electrophoresis and analyzed by western blotting. Tubulin and Lamin A were used as cytosolic and nuclear marker proteins respectively.

\section{Histone extraction}

Cells were harvested by scraping, pelleted and washed once in PBS. Pellets were suspended in $200 \mu \mathrm{l}$ Triton extraction buffer $\left(0.5 \%\right.$ Triton-x- $100,0.02 \% \mathrm{NaN}_{3}$, complete protease inhibitor tablet EDTA-free (Roche), PBS) and kept on ice for 10 min while gently vortexing. Then, samples were centrifuged at $4{ }^{\circ} \mathrm{C}$ with $400 \mathrm{~g}$ for $10 \mathrm{~min}$, the supernatants were removed, and the pellets were suspended in $100 \mu \mathrm{l}$ Triton extraction buffer and centrifuged as before. The pellets were suspended in $50 \mu \mathrm{l} 0.2 \mathrm{~N} \mathrm{HCl}$ and kept at $4{ }^{\circ} \mathrm{C}$ overnight while gently agitating. The samples were then centrifuged as before to extract the histones in the supernatant. Bradford assay (BioRad) was used to determine the concentration of the extracts. $2 \mu \mathrm{g}$ of histones were mixed with SDS-running buffer and denaturized $10 \mathrm{~min}$ at $99^{\circ} \mathrm{C}$. The samples were then loaded onto a $18 \%$ acrylamide gel and analyzed by western blotting using 4\% BSA in 0.5\% PBST for blocking and antibody dilutions.

\section{Cell proliferation assays}

Cell proliferation was determined using the $\mathrm{xCELLigence}$ RTCA system (Roche) or by counting with Trypan Blue staining using LUNA ${ }^{\text {TM }}$ Automated Cell Counter (Logos Biosystems). Real-time recording of cell proliferation with xCELLigence RTCA system was started $24 \mathrm{~h}$ after transfection with the indicated siRNAs. For A549 cells 2500 cells/well were seeded in 16 well E-plates (Roche). For GLC-2 15000 cells/well were used. For PC-9 and NCI-H2087 20000 cells/well were used. Cell indices were automatically recorded every $15 \mathrm{~min}$. For Trypan Blue proliferation assay $5 \times 10^{4}$ cells/well (siControl) or $1 \times 10^{5}$ cells/well (siKMT9 $\alpha \# 1$ ) were seeded onto 6 -well plates $24 \mathrm{~h}$ after treatment with siRNA. After $48 \mathrm{~h}, 72 \mathrm{~h}$ and $96 \mathrm{~h}$, supernatant, PBS from washing step and adherent cells harvested by trypsinization were counted and analyzed for viability using Trypan Blue staining and LUNA $^{\mathrm{TM}}$ Automated Cell Counter (Logos Biosystems). Population doubling time was calculated from 0 to $72 \mathrm{~h}$ (logarithmic growth) using Roth V. 2006 Doubling Time Computing [16].

\section{Flow cytometry for detection of apoptosis, cell cycle and granularity}

For apoptosis and cell cycle analysis, cells were trypsinized $24 \mathrm{~h}$ after treatment with siRNA and plated onto 6-well plates. One fraction was analyzed directly (day 1 ) and two more on day 2 and day 3. For apoptosis analysis cells were after trypsinization, washed in flow cytometry buffer (2\% FCS, 2 mM EDTA, PBS) and stained with Annexin V-FITC in binding buffer for $30 \mathrm{~min}$ at room temperature. 7-AAD was added 10 min prior to analysis. Reagents were used according to the manufacturer's protocol (Biolegend, Apoptosis Detection Kit). Cells double positive for Annexin V and PI were considered apoptotic. Cell cycle phase distribution was measured via DNA staining by propidium iodide (PI). To this end, trypsinized cells were washed in PBS, resuspended in $100 \mu \mathrm{l}$ PBS, fixed by adding $1 \mathrm{ml}$ ice-cold $70 \%$ ethanol dropwise while vortexing and kept at $-20{ }^{\circ} \mathrm{C}$ for at least $2 \mathrm{~h}$ prior to two wash steps in PBS (centrifuged with $500 \mathrm{~g}$, $3 \mathrm{~min}$ at room temperature). Staining was performed in $100 \mu \mathrm{l}$ PBS with $100 \mu \mathrm{g} / \mathrm{ml}$ RNAse A (Sigma) and $50 \mu \mathrm{g} / \mathrm{ml} \mathrm{PI}$ (Sigma) for $30 \mathrm{~min}$ at room temperature. Subsequently, cells were analyzed by recording at least 10,000 events and gated in PI-Area versus PI-Width channels. Cell cycle phase proportions were calculated by FlowJo 10.4 software. Cell granularity was measured at day 4 after transfection. In side scatter (SSC) versus forward scatter (FSC) contour plots (10\% level) of living single cells a gate "high granularity" was drawn just above the main population of cells treated with siControl and transferred to the cells treated with siKMT9 $\alpha$ to quantify population shift in SSC. Flow cytometry was done using BD LSR-Fortessa Cell Analyzer and data were analyzed with FlowJo software.

\section{RNA isolation}

Three days after transfection with siRNA as indicated, cells were harvested by scraping, washed in PBS and resuspended in $500 \mu \mathrm{l}$ TRIzol. Upon addition of $300 \mu \mathrm{l}$ chloroform samples were vortexed for $30 \mathrm{~s}$ and centrifuged $15 \mathrm{~min}$ at $4{ }^{\circ} \mathrm{C}$ with full speed. Then, the upper phase was transferred into a new tube containing $500 \mu \mathrm{l}$ isopropanol. The samples were vortexed $10 \mathrm{~s}$, incubated for $1 \mathrm{~h}$ at room temperature and centrifuged as before. Upon removal of the supernatants pellets were sequentially washed with $100 \%$ ethanol, followed by $75 \%$ ethanol in DEPC-treated $\mathrm{H}_{2} \mathrm{O}$ and allowed to air dry (approximately $30 \mathrm{~min}$ ). Finally, pellets were resuspended in $15 \mu \mathrm{l}$ DEPC- $\mathrm{H}_{2} \mathrm{O}$ and incubated for $10 \mathrm{~min}$ at $55{ }^{\circ} \mathrm{C}$. RNA concentration was measured by Nanodrop ND-1000 (Thermo Fisher).

\section{RNA sequencing (RNA-Seq)}

RNA samples were sequenced by the standard Illumina protocol to create raw sequence files (.fastq files) at the sequencing core facility of the DKFZ, Heidelberg. Reads were aligned to the hg19 build of the human genome 
using STAR version 2.5 [17]. The aligned reads were counted with the homer software (analyzeRepeats) and differentially expressed genes were identified using EdgeR [18]. $P$ value $<1^{*} 10^{-8}$ and $\log 2$ (fold-change) $>0.26$ or $\log 2$ (fold-change) $<(-0.26)$ were considered statistically significant. Gene set enrichment analysis (GSEA) was performed using the Broad Institute software [1921], false discovery rate $<10^{-5}$. Data are deposited under GSE131016.

\section{Quantitative real-time polymerase chain reaction (qRT-PCR)}

Quantitative RT-PCR was performed using the Abgene SYBR Green PCR kit (Invitrogen) according to the supplier's protocol. POLR2A was used for normalization. Primers for KMT9 $\alpha, Y E S 1, S O D 2$, TIMP2 and SMARCA2 were as follows: KMT9 $\alpha$ (5'-ACGTTTCTGCTTTTG GACGC- $3^{\prime}, \quad 5^{\prime}$-TCAGTGCACATGTACAAAGCC-3'); YES1 (5'-CGCCTGCAGATTCCATTCAG-3', 5'-GTC ACCCCTTATCTCATCCCA-3'); SOD2 (5'-TTTCAA TAAGGAACGGGGACAC-3', 5'-GTGCTCCCACAC ATCAATCC-3'); TIMP2 (5'-AAGCGGTCAGTGAGA AGGAAG-3', 5'-GGGGCCGTGTAGATAAACTCTAT3'); SMARCA2 (5'-GAAGCACCCAAAGCAAGTCA-3', 5'-TTCTCTTCGGTTTCCTGCCT-3').

\section{Proteomic sample preparation}

A549 cells transfected with siControl or siKMT9 $\alpha \# 1$ $(\mathrm{n}=4)$ were harvested 3 days after transfection. To ensure complete removal of cell culture media the cells were washed twice with $1 \mathrm{ml}$ PBS each time followed by centrifugation at $800 \mathrm{~g}$. Cell pellets were lysed using $300 \mu \mathrm{l} \mathrm{lysis}$ buffer for $10 \mathrm{~min}$ at $95^{\circ} \mathrm{C}$ and $750 \mathrm{rpm}$. The lysis buffer contained $0.1 \%$ RapiGest SF (Waters, Milford, MA), 0.1 M HEPES pH 8.0 (AppliChem, Darmstadt, Germany) and protease inhibitors: $10 \mu \mathrm{M}$ trans-epoxysuccinyl-L-leucylamido (4-guanidino)butane (E-64), $10 \mu \mathrm{M}$ E64d, $10 \mathrm{mM}$ phenylmethanesulfonyl fluoride (PMSF), $5 \mathrm{mM}$ ethylenediaminetetraacetic acid (EDTA) [22]. Samples were additionally sonicated using 20 cycles (30 s ON/OFF) at $4{ }^{\circ} \mathrm{C}$ in a Bioruptor device (Diagenode, Liège, Belgium). Afterwards, the protein concentration was determined using the bicinchoninic acid (BCA) assay (Thermo Scientific) and $100 \mu \mathrm{g}$ of protein from each sample was transferred to a fresh tube. Protein reduction was performed using $5 \mathrm{mM}$ dithiothreitol (DTT) (AppliChem, Darmstadt, Germany, 15 min at $37{ }^{\circ} \mathrm{C}, 750 \mathrm{rpm}$ agitation). Free thiols were alkylated by $15 \mathrm{mM}$ 2-iodoacetamide (IAM) and incubated for $15 \mathrm{~min}$ at $37{ }^{\circ} \mathrm{C}$ in the dark without mixing. Tryptic in-solution digestion was performed by adding sequencing grade trypsin (Worthington, 1:25 enzyme:protein ratio) to each sample and incubating at $50{ }^{\circ} \mathrm{C}$ for $2 \mathrm{~h}$ at $750 \mathrm{rpm}$ agitation [23] followed by a second digestion step at $37{ }^{\circ} \mathrm{C}, 18 \mathrm{~h}$ at $500 \mathrm{rpm}$. Samples were then acidified by adding trifluoroacetic acid (TFA) to a final concentration of $2 \%$ and incubated for $30 \mathrm{~min}$ at $37{ }^{\circ} \mathrm{C}$ to degrade the acid-labile surfactant RapiGestSF. All samples were desalted using iST columns according to the manufacturers protocol (PreOmics, Martinsried, Germany) [24]. The peptide concentration was measured using BCA and $25 \mu \mathrm{g}$ of each sample was transferred to a fresh microreaction tube and vacuum-concentrated until dryness. Samples were resuspended in $50 \mu \mathrm{l} 0.1 \mathrm{M}$ HEPES $\mathrm{pH}$ 8.0. For internal quantification control the samples were divided in two groups and different amounts $(600 \mathrm{fmol}$ vs. $1000 \mathrm{fmol}$ ) of 11 synthetic peptides were spikedin [25]. Samples including the synthetic peptides were labeled using TMT-10-plex (Thermo Scientific) at room temperature overnight with $550 \mathrm{rpm}$ agitation [26]. All samples were combined and $45 \mu \mathrm{g}$ of the mixture were fractionated by high $\mathrm{pH}$ reversed phase chromatography [XBridge C18 column, $150 \mathrm{~mm} \times 1 \mathrm{~mm}$ column containing $3.5 \mu \mathrm{m}$ particles (Waters)]. An increasing linear gradient of acetonitrile from 10 to $45 \%$ over $45 \mathrm{~min}$ at a flowrate of $42 \mu \mathrm{l} / \mathrm{min}$ was applied using an Agilent 1100 HPLC system. 24 fractions were collected and concatenated into 12 fractions (combining fraction 1 with fraction 13, fraction 2 with fraction 14 and so on). The resulting 12 fractions were vacuum-concentrated until dryness and stored at $-80^{\circ} \mathrm{C}$ until LC-MS/MS analysis.

\section{Liquid chromatography-tandem mass spectrometry}

Each fraction was dissolved in $40 \mu \mathrm{l}$ buffer A containing $0.1 \%$ formic acid in water (Honeywell) and sonicated for $5 \mathrm{~min}$ in a sonication water bath. Samples were separated using an EASY-nLC ${ }^{\mathrm{TM}} 1000$ UHPLC system (Thermo Scientific) at a flow rate of $200 \mathrm{nl} / \mathrm{min}$. Prior to the separation, the injected sample ( $6 \mu \mathrm{l}$ per fraction) was trapped on a PepMAP100 C18 nanoViper trapping column (20 mm $\times 75 \mu \mathrm{m}, 3 \mu \mathrm{m}$ particles). The analytical column was an EASY-Spray ${ }^{\mathrm{TM}}$ C18 column $(250 \mathrm{~mm} \times 75 \mu \mathrm{m}$, $2 \mu \mathrm{m}$ particles heated at $50{ }^{\circ} \mathrm{C}$ ). For peptide separation, we used a linear gradient of increasing buffer $\mathrm{B}$ ( $0.1 \%$ formic acid in acetonitrile, Fluka), ranging from 5 to $25 \%$ acetonitrile over the first $60 \mathrm{~min}$ and from 25 to $60 \%$ acetonitrile in the subsequent $30 \mathrm{~min}$ (90 min separating gradient length). Peptides were analyzed using a Q-Exactive Plus mass spectrometer (Thermo Scientific, San Jose, CA) operating in a data dependent acquisition (DDA) mode. Survey scans were performed at 70,000 resolution, an AGC target of $3 \mathrm{e} 6$ and a maximum Injection time of $50 \mathrm{~ms}$ followed by targeting the top 10 precursor ions for fragmentation scans at 35,000 resolution with $1.2 \mathrm{~m} / \mathrm{z}$ isolation windows, an NCE of 32 and an dynamic exclusion time of $40 \mathrm{~s}$. For all ms2 scans the 
intensity threshold was set to 1000, the AGC to 1e5, maximum Injection time of $100 \mathrm{~ms}$ and the fixed first mass to $100 \mathrm{~m} / \mathrm{z}$. The mass spectrometry proteomics data have been deposited to the ProteomeXchange Consortium [27] via the PRIDE [28] partner repository with the dataset identifier PXD014145.

\section{Liquid chromatography-tandem mass spectrometry data analysis}

Raw data were analyzed using MaxQuant ( $\mathrm{v}$ 1.6.0.2) and a human proteome database (reviewed sequences, downloaded from uniprot.org on June 6th, 2017, containing 20188 entries and 11 additional sequences for the iRT peptides). In MaxQuant the PIF was set to 0.75 and up to two missed cleavages were allowed using the Trypsin/P enzymatic specificity. Protein N-term acetylation and oxidation of methionine were set as variable modifications whereas carbamidomethylation of cysteine was set as a fixed modification. Unique and razor peptides were used for protein quantification, allowing for protein quantification based on only one peptide. The results were further processed using $\mathrm{R}(\mathrm{v}$ 3.5.2) and RStudio ( $\mathrm{v}$ 1.1.456). First all contaminants, reverse hits and spikedin peptides were removed as well as proteins which were only identified by site. Subsequently, protein intensities were $\log 2$ transformed and normalized across all samples using median polish. To identify differentially expressed proteins, we used the limma package (v 3.40.0). Only proteins with an adjusted $\mathrm{P}$-value $<0.05$ were considered as being significantly dysregulated. Those proteins were then combined with the genes found significantly dysregulated in the RNA-Seq experiments resulting in a comprehensive dataset containing transcriptome and proteome information.

\section{Data analysis}

TCGA data was accessed and analyzed by using UALCAN [29]. The t test was performed using a PERL script with Comprehensive Perl Archive Network (CPAN) module "Statistics::TTest". Survival data of GSE26939 data set was obtained and analyzed using PROGgeneV2 program [30,31]. Briefly, hazard ratio and confidence interval were determined by cox proportional hazards analysis using 'coxph' function in R library 'survival', the Kaplan-Meier plot was created using 'surfit' function in $\mathrm{R}$ library 'survival'. Prism 6 was used for statistical calculations. Data are presented as means \pm standard deviation or means + standard deviation. Significance was calculated by two-tailed paired $\mathrm{t}$ test.

\section{Results}

To address KMT9 expression in lung cancer we analyzed RNA-Seq data of matched normal and stage 1a lung adenocarcinoma tissue from eleven patients (GSE83213) and found that KMT9 $\alpha$ expression was increased in seven tumor samples (Fig. 1a). This initial observation prompted us to analyze larger cohorts such as the TCGA cohort presented in Fig. 1b. There, KMT9 $\alpha$ expression in lung adenocarcinoma is significantly increased compared to normal lung tissue in unpaired samples. Additional file 8 a shows KMT9 $\alpha$ expression for individual tumor stage in the TCGA cohort with a significant increase of $K M T 9 \alpha$ in stage 1 and stage 3 . Additional file $8 \mathrm{~b}$ shows KMT9 $\alpha$ expression for individual histopathologic subtypes of lung adenocarcinoma. The clinical relevance of KMT9 $\alpha$ in lung cancer was revealed by analyzing a cohort of patients with lung adenocarcinoma divided into high expression $(n=58)$ and low expression $(n=57)$ of KMT9 $\alpha$ (GSE26939). As shown in Fig. 1c, patients with low expression of KMT9 $\alpha$ in their tumor have a higher 5 -year and overall survival rate than patients with high expression of KMT9 $\alpha$ [32]. In Fig. 1d we show that protein levels of KMT9 $\alpha$ and $\beta$ are increased in lung cancer tissue compared to patient-matched normal lung tissue. Next, we wondered whether KMT9 is present in lung cancer cells. Our western blot analysis in Fig. 1e indicate that both KMT9 $\alpha$ and KMT9 $\beta$ are present in small cell lung cancer (GLC-2 and NCI-H82) and NSCLC adenocarcinoma (A549, PC-9 and NCI-H2087) cells with various mutations such as KRAS and CDKN2A mutated A549; CDKN2A, EGFR and TP53 mutated PC-9; and BRAF and TP53 mutated NCI-H2087 cells [33]. Immortalized lung fibroblast cell lines (IMR-90 and CRL-7000) were included as a non-cancer control and reveal equal amounts of KMT9 $\alpha$ and a slightly reduced expression of KMT9 $\beta$. We investigated the cellular distribution of KMT9 in the lung adenocarcinoma cell line A549 cells. Upon cell fractionation, lysates of cytosolic and nuclear fraction were analyzed by western blot. As shown in Fig. 1f, KMT9 $\alpha$ and KMT9 $\beta$ were found present in the cytoplasm and the nucleus of A549 cells. Since KMT9 writes the histone mark H4K12me1, we wondered whether the mark is present in various lung cancer cells. Western blot analysis revealed presence of H4K12me1 in the analyzed lung cancer cells (Fig. 1g). Here we show that KMT9 is present in lung cancer tissue and cell lines and that the level of KMT9 in lung adenocarcinoma accounts for patient survival.

Since KMT9 has been shown to regulate gene expression [9] we next performed global transcriptome analyses (RNA-Seq) in A549 cells treated with siControl or siKMT9 $\alpha \# 1$ and identified 6614 differentially expressed genes upon KMT9 $\alpha$ knock-down (Fig. 2a). In parallel, 


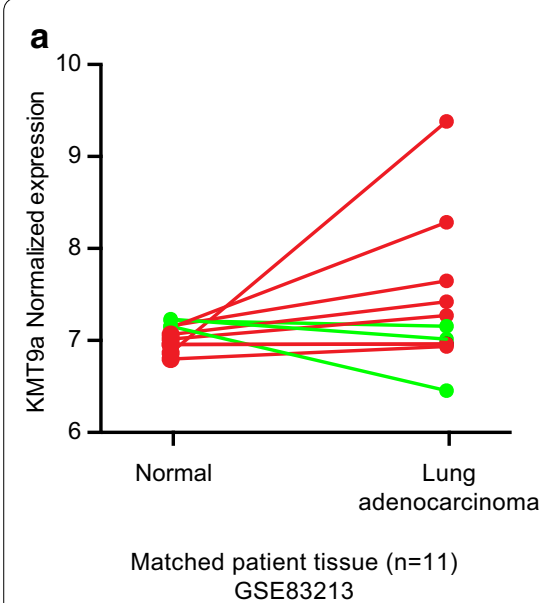

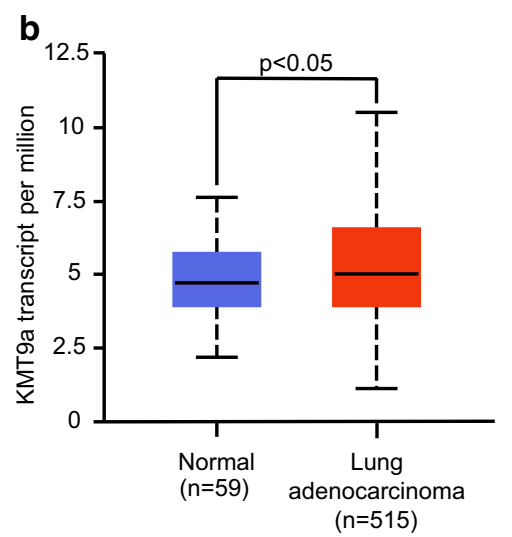

TCGA samples
C

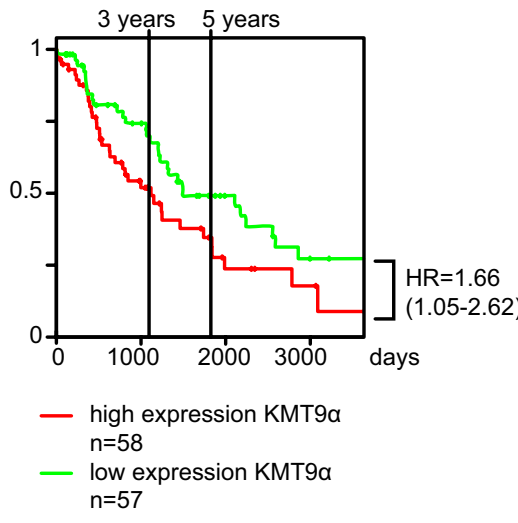

GSE26939 d

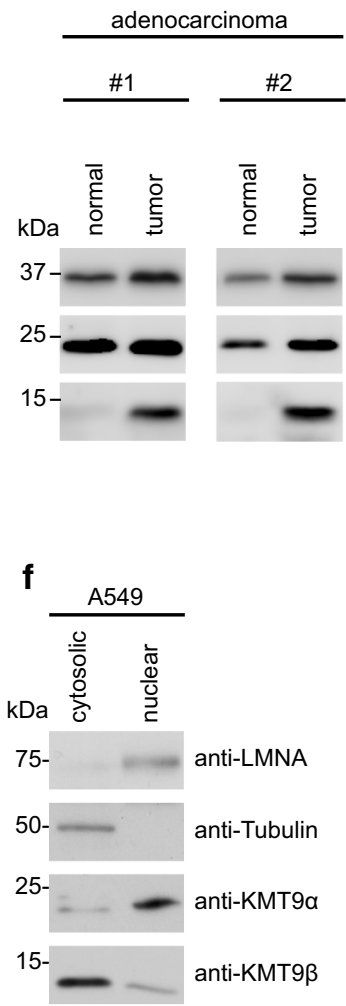

small cell lung cancer
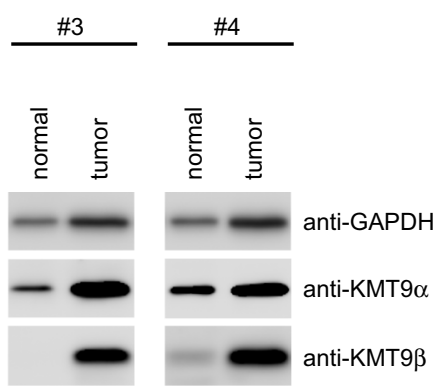

$\mathbf{g}_{\text {small cell }}$ lung cancer adenocarcinoma e

\begin{tabular}{|c|c|c|}
\hline & cancer & normal \\
\hline small cell & adenocarcinoma & $\begin{array}{l}\text { lung } \\
\text { fibroblasts }\end{array}$ \\
\hline
\end{tabular}
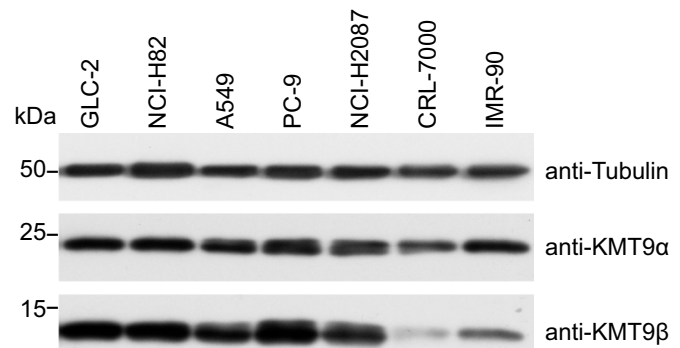

Fig. 1 KMT9 is expressed in lung cancer tissue and cell lines. a Dynamics of KMT9a expression in matched normal and stage 1a lung adenocarcinoma tissue from eleven patients that underwent curative lobectomy. Normal samples were taken at $6 \mathrm{~cm}$ distance from macroscopic tumor sites. Data were extracted from (GSE83213). Red lines indicate increased expression of KMT9a in tumor ( $\mathrm{n}=8$ ), green lines indicate decreased expression of KMT9a in tumor $(n=3)$. b TCGA data comparing KMT9a expression in $n=515$ lung adenocarcinoma with non-matched normal lung tissue $(n=59)$. Data represent interquartile range including minimum, 25th percentile, median, 75 th percentile and maximum values. Significance was accessed by t test. c Kaplan-Meier survival analysis of patients with adenocarcinoma expressing high ( $\mathrm{n}=58)$ and low $(\mathrm{n}=57) \mathrm{KMT9}$. Data were extracted from GSE26939. HR= hazard ratio. d Western blots of matched tissue from normal and tumor samples from patients with adenocarcinoma (\#1 and \#2) or SCLC (\#3 and \#4). Western blots were performed with the indicated antibodies. e Expression levels of KMT9a and KMT9 $\beta$ in human cell lines from SCLC (GLC-2 and NCl-H82), adenocarcinoma (A549, PC-9 and NCl-H2087) and human immortalized normal lung fibroblasts (CRL-7000 and IMR-90) were analyzed by western blot using the indicated antibodies. f In A549 cells, KMT9a and KMT9 $\beta$ are present in both nuclear and cytoplasmic compartments. Western blots were performed with the indicated antibodies. $\mathbf{g}$ Levels of H4K12me1 in SCLC (GLC-2 and $\mathrm{NCl}-\mathrm{H} 82$ ) and adenocarcinoma (A549, PC-9 and NCl-H2087) cells were analyzed by western blotting using the indicated antibodies 


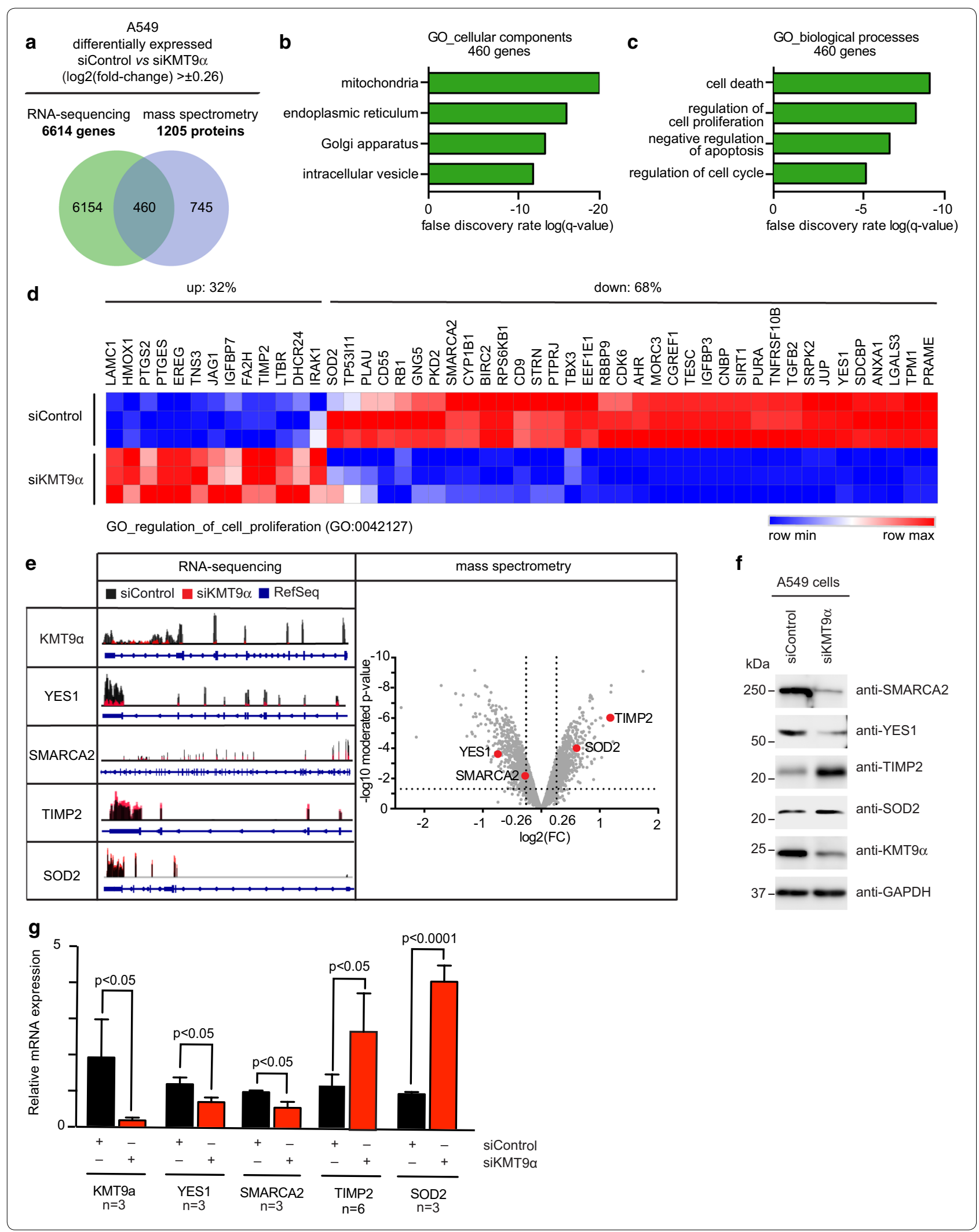




\section{(See figure on previous page.)}

Fig. 2 KMT9 controls expression of genes involved in the organization of organelles, cells death and cell proliferation. a Venn diagram showing overlap and number of genes/proteins in A549 cells that are differentially expressed upon RNAi mediated knock-down of KMT9a (log2(fold-change) $> \pm 0.26$ ). In total, 460 targets are concomitantly up- or down-regulated on RNA and protein level upon knock-down of KMT9a. Enriched GO_cellular components b and GO_biological processes c gene sets obtained for the indicated 460 KMT9a-regulated target genes. d Heat map displaying mRNA levels of the 460 KMT9a-regulated genes involved in cell proliferation (GO:0042127) in A549 cells treated with siControl or siKMT9a\#1. e RNA sequencing reads (left panel) and mass spectrometry volcano plot (right panel) for the indicated genes and proteins are represented exemplarily. $\mathbf{f}$ Western blot displaying expression of the target proteins indicated in e upon knock-down of KMT9a in A549 cells. The indicated antibodies were used. $\mathbf{g}$ Quantitative real-time PCR analysis of the mRNA expression of the target genes displayed in $\mathbf{e}$ after knock-down of KMT9a. Data represent means + standard deviation. Significance was accessed by two-tailed t test, $n=3(\operatorname{TIMP2} n=6)$

we also performed a global, quantitative proteome analysis (using tandem mass tag multiplexing) in A549 cells treated with siControl or siKMT $9 \alpha \# 1.1205$ proteins displayed significant (limma moderated t-statistics) quantitative changes upon KMT9 $\alpha$ knock-down (Fig. 2a). Intersection of the transcriptome and the proteome data unraveled 460 targets being up- or down-regulated concomitantly on both mRNA and protein level (Fig. 2a, e). We focused on this concomitantly regulated core set of genes in order to primarily investigate KMT9-dependent expression alterations for which the affected mRNA levels display strong penetration into the proteome level.

To decipher the biological functions of these 460 target genes, we performed gene enrichment analyses. The enrichment analysis for cellular components (Fig. 2b) uncovered genes involved in subcellular organelles such as "mitochondria", "endoplasmic reticulum", "Golgi apparatus" or "intracellular vesicles" The enrichment analysis for biological processes (Fig. 2c) revealed genes accounting for "cell death", "regulation of proliferation", as well as "regulation of cell cycle" among the top-ranking categories. RNA-Seq counts for the covered genes of the "GO_ regulation_of_cell_proliferation" gene set are displayed as a heat map in Fig. 2d. Individual RNA-Seq and mass spectrometry data for important regulatory downstream targets of KMT9 are provided in Fig. 2e. These target genes and proteins were additionally validated by western blot (Fig. 2f) and qRT-PCR (Fig. 2g) analyses. We show that KMT9 controls expression of genes involved in the organization of organelles and regulating cell proliferation.

To corroborate the transcriptome and the proteome data, we analyzed the biological impact of KMT9 depletion in A549 cells by flow cytometry. As shown in Fig. 3a, b, the percentage of cells showing high granularity increased dramatically upon KMT9 $\alpha$ knock-down as would be expected if major changes have occurred in the subcellular organelles. Increase in granularity is associated with physiological processes such as terminal growth arrest and cell death. We therefore measured the population doubling time and the cell viability in A549 cells cultured in the presence of siControl or siKMT9\#1. As shown, the population doubling time of A549 cells increased upon knockdown of KMT9 $\alpha$ (Fig. 3c, d) and cell viability decreased (Fig. 3e). The experiment shown in Fig. 3f, g indicate that no increase in apoptosis was observed in A549 cells upon siKMT9 $\alpha$ mediated knock-down, suggesting that the decrease in cell viability results from non-apoptotic cell death. In addition, no significant alteration of cell cycle phase distribution was detected at day 1, day 2 or day 3 after RNAi transfection (Fig. 3h, i). Here we observed that knock-down of KMT9 $\alpha$ in A549 cells leads to inhibition of proliferation and induction of non-apoptotic cell death.

\footnotetext{
(See figure on next page.)

Fig. 3 Knock-down of KMT9a inhibits A549 lung cancer cell proliferation and induces non-apoptotic cell death. a, b The granularity of A549 cells with siControl or siKMT9a\#1 was measured by flow cytometry using side scatter (SSC). a Figure exemplifying the gating strategy used to assess size of "high granularity" population of A549 cells treated with siControl and siKMT9a\#1. b Column graph showing the percentage of A549 cells with "high granularity" upon treatment with siControl or siKMT9a\#1. Data represent means + standard deviation. Significance was accessed by two-tailed paired $t$ test, $n=3$. c-e Proliferation assay. $\mathbf{c}$ Representative proliferation curve of A549 cells treated with siControl or siKMT9a\#1. Data represent mean \pm standard deviation. The experiment was repeated three times independently. $\mathbf{d}$ Column graph representing the population doubling time $(0-72 \mathrm{~h})$. Data represent means + standard deviation. Significance was accessed by two-tailed paired $t$ test, $n=3$. e Column graph representing the percentage of living cells $72 \mathrm{~h}$ after starting the experiment. Data represent means + standard deviation. Significance was accessed by two-tailed paired $t$ test, $n=3$. f, $\mathbf{g}$ Apoptosis assay. Apoptotic A549 cells treated with siControl or sikMT9a\#1 were identified by flow cytometry using Annexin $V$ and 7-AAD staining. $\mathbf{f}$ Day 2 of one representative experiment is shown. $\mathbf{g}$ Bar graphs representing the percentage of A549 apoptotic cells upon treatment with siControl or siKMT9a\#1 on days 1-3. Columns represent means + standard deviation. Significance was assessed by two-tailed paired t test, $n=3$. $\mathbf{h}$, i Cell cycle phase distribution was assessed in A549 cells treated with siControl or siKMT9a\#1 by propidium iodide (PI) staining and flow cytometry. $\mathbf{h}$ Day 3 of one representative experiment is shown. $\mathbf{i}$ Bar graphs representing percentage of cells per cell cycle phase in A549 cells treated with siControl or siKMT9a\#1 on days 1-3. Data represent means + standard deviation. Significance was assessed by two-tailed paired t test, $\mathrm{n}=3$. SSC side scatter, FSC forward scatter; ns: not significant
} 

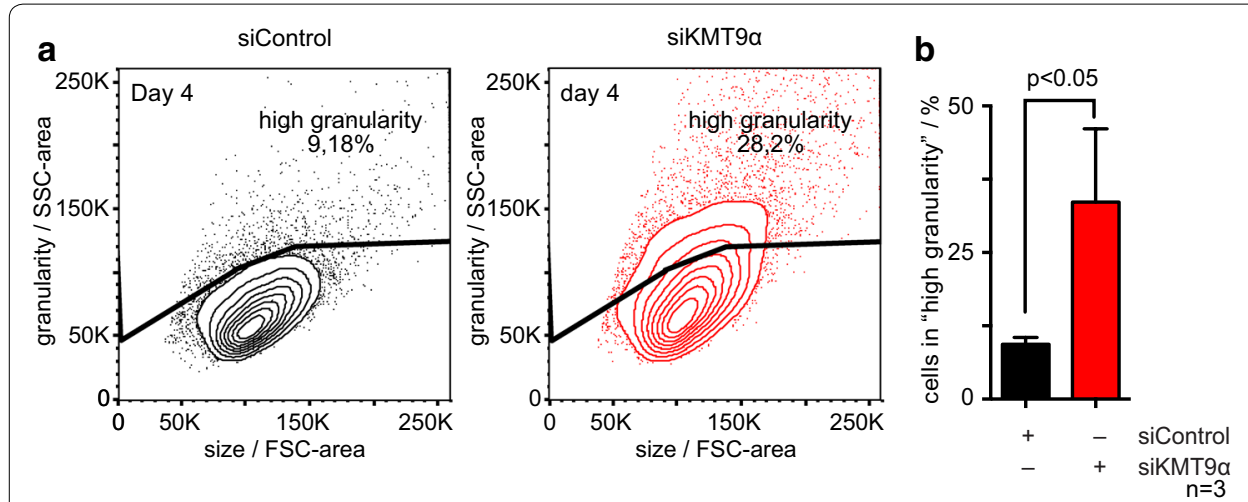

C
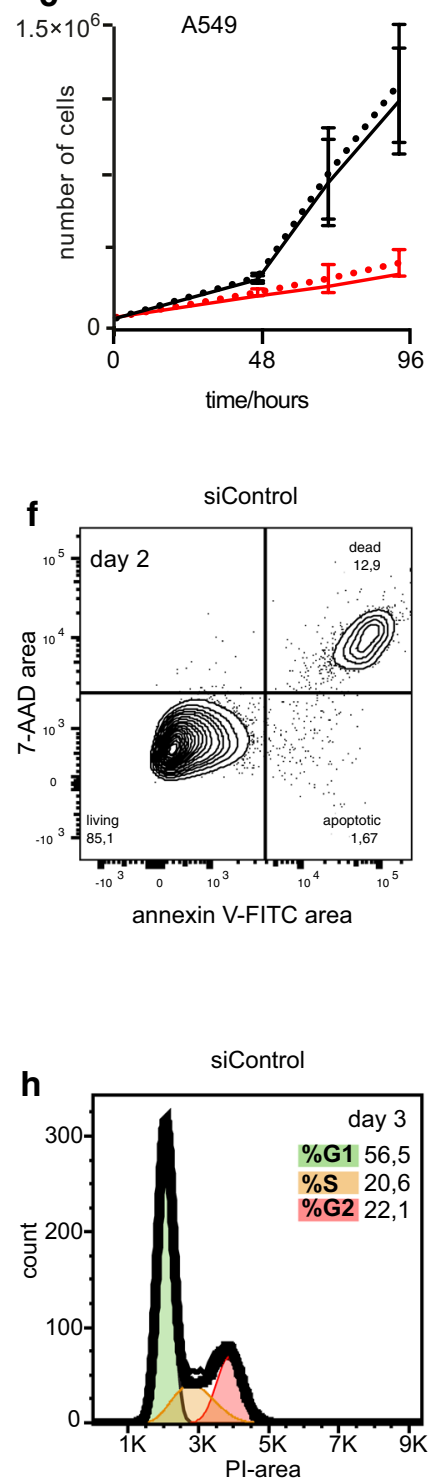

- total cells siControl

- living cells siControl

- total cells siKMT9a

- living cells siKMT9a\#1

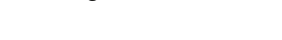

d

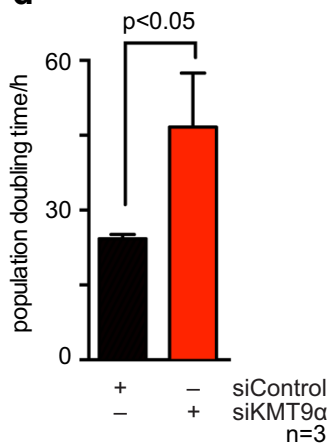

e

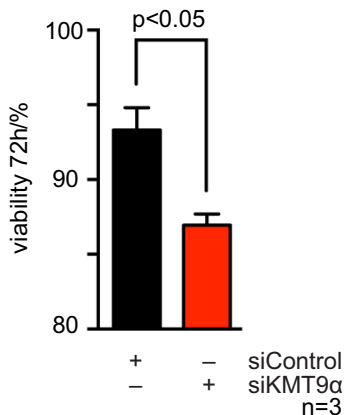

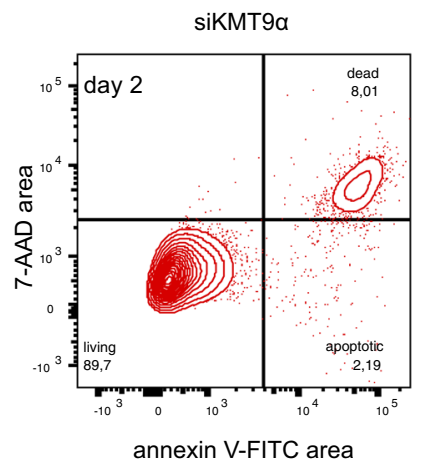

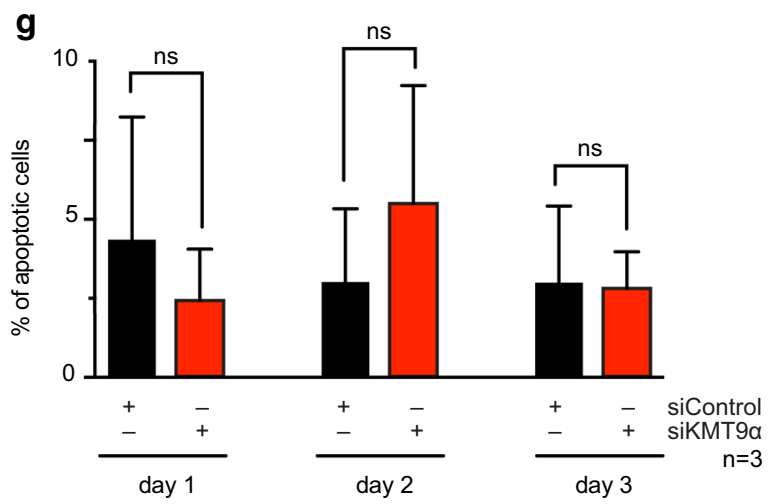

siKMT9a

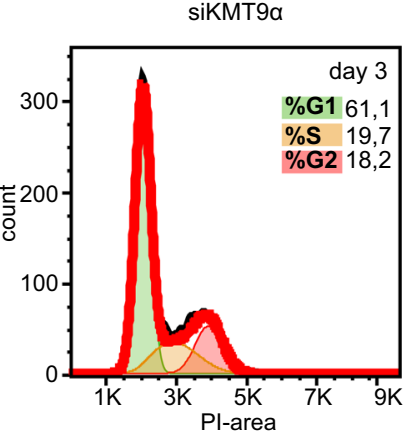


a small cell lung cancer

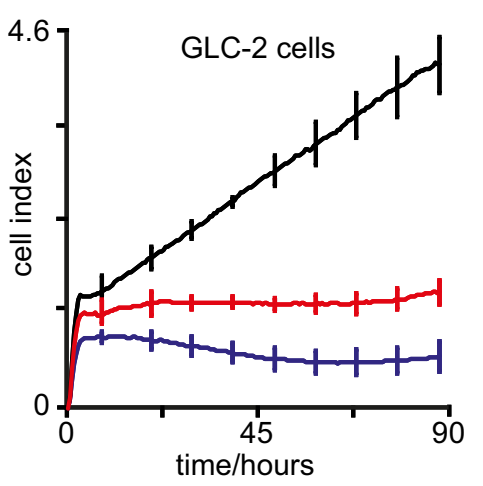

$$
\begin{aligned}
& \text { - siControl } \\
& \text { - siKMT9a\#1 } \\
& \text { - siKMT9a\#2 }
\end{aligned}
$$

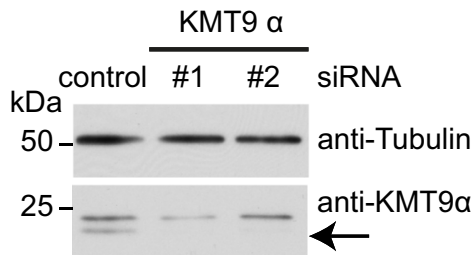

C adenocarcinoma

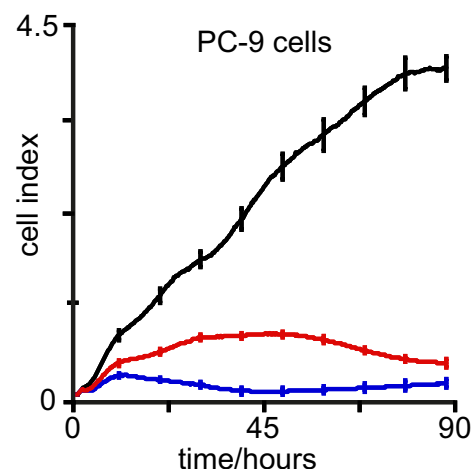

- siControl

- siKMT9a\#1

- siKMT9a\#2

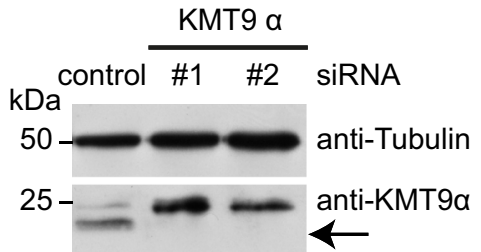

b adenocarcinoma

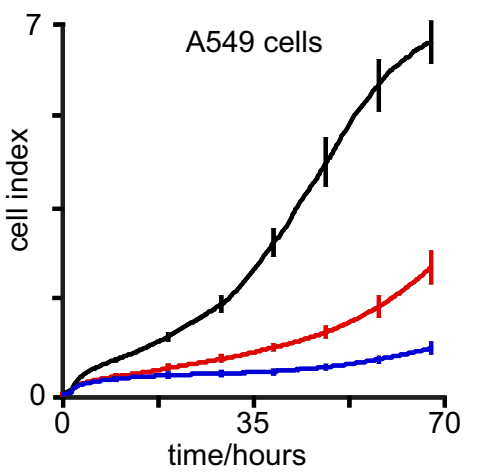

-siControl

- siKMT9a\#1

- siKMT9a\#2

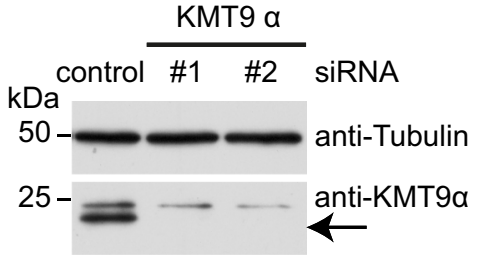

d adenocarcinoma
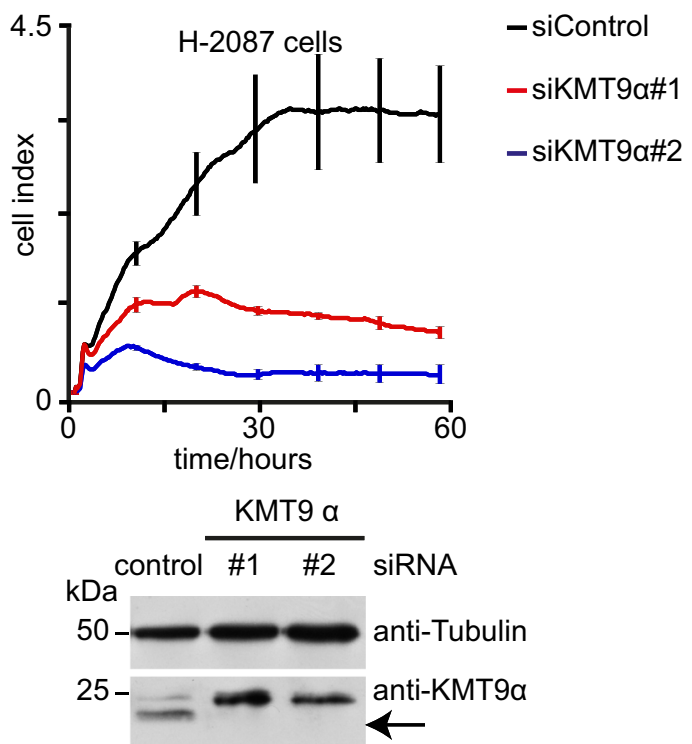

Fig. 4 KMT9a controls proliferation of small cell lung cancer and lung adenocarcinoma cell lines. a-d Real-time proliferation of GLC-2 (a), A549 (b), PC-9 (c) and NCI-H2087 (d) cells upon transfection with siControl, siKMT9a\#1 or siKMT9a\#2. For each cell line one representative experiment is shown (mean \pm standard deviation from four technical replicates). Each experiment was performed at least three times independently. Western blot analyses were performed with the indicated antibodies to verify knock-down of KMT9a 
Since KMT9 was found to be present in lung cancer cell lines we wondered whether the anti-proliferative effect of siRNA mediated knock-down of KMT9 $\alpha$ in A549 lung adenocarcinoma cells could also be observed in other lung cancer cell lines. Therefore, we performed RNAi mediated knock-down of KMT $\alpha \alpha$ in the small cell lung cancer cell line GLC-2 and the adenocarcinoma cell lines A549, PC-9 and NCI-H2087 and monitored realtime proliferation. As shown in Fig. 4a-d, loss of KMT9 $\alpha$ severely interferes with proliferation of all tested cell lines. Knock-down efficiency was verified by western blot analyses. These data clearly demonstrate that KMT9 is a global regulator of lung cancer cell proliferation.

\section{Discussion}

We showed that the recently described novel histone methyltransferase KMT9 is expressed in lung cancer cell lines and regulates proliferation and survival of small cell lung cancer and NSCLC lines harboring various mutations.

Recently, Metzger et al. [9] discovered KMT9 $\alpha$ to be a novel histone methyltransferase that regulates prostate tumor proliferation. Here, we investigated four lung cancer cell lines and found that upon KMT9 $\alpha$ knock-down proliferation of all of them was blocked. In PC-3M prostate cancer cells the anti-proliferative effect was reported to be accompanied by apoptosis and cell cycle arrest and therefore distinct from our observations in A549 cells. This could indicate a role of KMT9 in maintaining the cancer epigenome up-stream of the subtype specific mechanisms by which each cancer cell evades anti-proliferative and cell death signaling. Non-apoptotic cell death, also called regulated necrosis, is of increasing interest in cancer research [34]. Deciphering the exact pathway by which the knockdown of KMT9 $\alpha$ leads to non-apoptotic cell death should be investigated in future studies. Recently, Li et al. [35] have correlated N6AMT1 expression with m6dA marks in murine neurons that are associated with activity-induced gene expression. Notably, the experiments by Li et al. were performed in post-mitotic neurons suggesting that the functions of KMT9 include but are not limited to regulating proliferation. Here we report major alterations in gene and protein expression of A549 cells after knock-down of KMT $9 \alpha$ indicating the comprehensive role of KMT9 as it would be expected of a bona fide histone methyltransferase. Future research will unravel to what extend KMT9 is a global epigenetic effector in tumor cell proliferation asides from prostate and lung cancer entities.

The development of lung cancer is characterized by continuous genetic and epigenetic alterations. A plethora of driver and passenger mutations has been identified to participate in cancerogenesis of lung cancer. Stage four
NSCLC harboring EGFR mutation was the first cancer entity to be treated with a targeted therapy in first line treatment $[11,36,37]$. Today, a growing number of targeted inhibitors are used in molecular treatment of lung cancer depending on the individual mutational status. These therapies are effective but their application is limited to a small patient clientele and in most cases the tumors develop resistance mutations within short notice. Knock-down of the histone methyltransferase KMT9 $\alpha$ succeeded to block proliferation of all tested lung cancer cell lines independent of their mutation profile. Targeting chromatin modifying enzymes such as histone methyltransferases represent promising targets for stable therapeutic results in epigenetic therapy and inhibitors of histone methyltransferase EZH2 [38] and histone demethylase LSD1 [39] have already entered clinical trials (NCT03460977, NCT02913443, NCT03337698). Our characterization of the recently discovered histone methyltransferase KMT9 as a prominent regulator of lung cancer cell survival and proliferation paves the way for KMT9 inhibitors to be evaluated as a highly needed additional treatment option in multimodal lung cancer therapy.

\section{Conclusions}

In conclusion, our data demonstrate that the novel histone methyltransferase KMT9 is crucial for proliferation and survival of small cell lung cancer and lung adenocarcinoma cells. Our data link full transcriptome and proteome analyses with functional biological experiments on proliferation and survival thereby identifying 460 genes that are deregulated upon knock-down of KMT $9 \alpha$ in A549 cells. These genes cluster with proliferation, cell cycle and cell death gene sets as well as with subcellular organelles in gene ontology analysis. In flow cytometry, we observed major changes in granularity of A549 cells depleted of KMT9 $\alpha$ and increased non-apoptotic cell death. Our results are paving the way for small molecules targeting KMT9 to be evaluated as a highly needed new therapeutic approach for lung cancer treatment.

\section{Supplementary information}

Supplementary information accompanies this paper at https://doi. org/10.1186/s12935-020-1141-2.

Additional file 1. Certificate GLC-2. Results and certificate of STR-profiling and cell authentication.

Additional file 2. Certificate NCl-H82. Results and certificate of STRprofiling and cell authentication.

Additional file 3. Certificate A549. Results and certificate of STR-profiling and cell authentication.

Additional file 4. Certificate PC-9. Results and certificate of STR-profiling and cell authentication. 
Additional file 5. Certificate NCl-H2087. Results and certificate of STRprofiling and cell authentication.

Additional file 6. Certificate CRL-7000. Results and certificate of STRprofiling and cell authentication. "HS 1.Lu" is a synonym of CRL-7000.

Additional file 7. Certificate IMR-90. Results and certificate of STR-profiling and cell authentication.

Additional file 8. KMT9a expression is significantly increased in stage 1 and 3 lung adenocarcinoma from the TCGA cohort. a TCGA lung adenocarcinoma samples were divided according to stage and the KMT9a expression analyzed. Data represent interquartile range including minimum, 25th percentile, median, 75th percentile and maximum values. Significance was accessed by $t$ test. b TCGA lung adenocarcinoma samples were divided according to histopathologic subtypes and the KMT9a expression analyzed. Data represent interquartile range including minimum, 25th percentile, median, 75th percentile and maximum values. Significance was accessed by $t$ test. Subgroups with $p$-value $<0.05$ when compared to normal are marked by "**".

\section{Abbreviations}

NSCLC: Non-small cell lung cancer; SCLC: Small cell lung cancer; SSC: Side scatter; FSC: Forward scatter; RNA-Seq: RNA sequencing; qRT-PCR: Quantitative real-time polymerase chain reaction.

\section{Acknowledgements}

We are obliged to Astrid Rieder, Dr. Sylvia Urban and Manuela Sum for providing excellent technical assistance and to Dr. Dominica Willmann for her assistance with bioinformatics analyses. We thank Dr. Martin Biniossek for excellent support of LC-MS/MS experiments.

\section{Authors' contributions}

RS and EM generated the original hypothesis. HMB performed and analyzed all cell culture experiments, analyzed RNA-Seq and mass spectrometry data and took primary responsibility for writing the manuscript. EM contributed to the manuscript. MF performed and analyzed mass spectrometry analysis. JG and RKT provided patient-matched expression data. OS planned and supervised mass spectrometry experiments. All authors provided intellectual contributions throughout the project. All authors read and approved the final manuscript.

\section{Funding}

This work was supported by grants of the Deutsche Forschungsgemeinschaft (DFG, German Research Foundation): SFB 850, 992,1381 (Project-ID 403222702), and Schu688/15-1 as well as the Signalling Research Centres BIOSS and CIBSS: CIBSS—EXC-2189_-Project ID 390939984 to Professor Roland Schüle, Department of Urology, Head of Center for Clinical Research, Medical Center University of Freiburg.

O.S. acknowledges support by Deutsche Forschungsgemeinschaft (GR 1748/6-1, PA 2807/3-1, SCHI 871/8-1, SCHI 871/9-1, SCHI 871/11-1, INST 39/900-1, INST 380/124-1, and SFB850-Project Z1 (INST 39/766-3)), the German-Israel Foundation (Grant No. I-1444-201.2/2017), and the ERAPerMed (BMBF) program on personalized medicine (projects 01 KU1915A and 01KU1916A).

The article processing charge was funded by the German Research Foundation (DFG) and the University of Freiburg in the funding program Open Access Publishing.

\section{Availability of data and materials}

The transcriptomic dataset generated and analyzed during the current study are available in the GEO repository, GSE131016. The proteomic dataset generated and analyzed during the current study are available in the PRIDE partner repository with the dataset identifier PXD014145.

\section{Ethics approval and consent to participate}

Human tissue samples were obtained from patients under institutional review board (IRB)-approved protocols following written informed consent. The institutional review board of the University of Cologne approved the study of these cases. The tumor samples were histologically assessed to have a purity of at least $70 \%$, and the matched normal tissue was confirmed to be free of tumor cells.

\section{Consent for publication}

Not applicable.

\section{Competing interests}

The authors declare that they have no competing interests.

\section{Author details}

${ }^{1}$ Klinik für Urologie und Zentrale Klinische Forschung, Medizinische Fakultät, Albert-Ludwigs-Universität Freiburg, Universitätsklinikum Freiburg, Freiburg, Germany. ${ }^{2}$ Institute for Surgical Pathology, Medical Center - University of Freiburg, Faculty of Medicine, University of Freiburg, Freiburg, Germany. ${ }^{3}$ Faculty of Biology, Albert-Ludwigs-University Freiburg, Freiburg, Germany.

${ }^{4}$ Spemann Graduate School of Biology and Medicine (SGBM), Albert-LudwigsUniversity Freiburg, Freiburg, Germany. ${ }^{5}$ Department of Translational Genomics, Center of Integrated Oncology Cologne-Bonn, Medical Faculty, University of Cologne, 50931 Cologne, Germany. ${ }^{6}$ Department of Pathology, University Hospital Cologne, 50937 Cologne, Germany. ${ }^{7}$ German Cancer Research Center, German Cancer Consortium (DKTK), Heidelberg, Germany. ${ }^{8}$ Deutsches Konsortium für Translationale Krebsforschung, Standort Freiburg, Freiburg, Germany. ${ }^{9}$ BIOSS Centre of Biological Signalling Studies, Albert-Ludwigs-University Freiburg, Freiburg, Germany. ${ }^{10} \mathrm{CIBSS}$ Centre for Integrative Biological Signalling Studies, Albert-Ludwigs-University Freiburg, Freiburg, Germany.

${ }_{11}$ K-metics GmbH, Freiburg, Germany.

Received: 28 October 2019 Accepted: 10 February 2020

Published online: 17 February 2020

\section{References}

1. Bray F, Ferlay J, Soerjomataram I, Siegel RL, Torre LA, Jemal A. Global cancer statistics 2018: GLOBOCAN estimates of incidence and mortality worldwide for 36 cancers in 185 countries. CA Cancer J Clin. 2018. https:// doi.org/10.3322/caac.21492.

2. Feinberg AP, Vogelstein B. Hypomethylation distinguishes genes of some human cancers from their normal counterparts. Nature. 1983;301:89-92.

3. Hanahan D, Weinberg RA. Hallmarks of cancer: the next generation. Cell. 2011;144:646-74.

4. Holliday R. The inheritance of epigenetic defects. Science (80-). 1987;238:163-70.

5. Strahl $B D$, Allis $C D$. The language of covalent histone modifications. Nature. 2000;403:41-5.

6. Chen Y, Liu X, Li Y, Quan C, Zheng L, Huang K. Lung cancer therapy targeting histone methylation: opportunities and challenges. Comput Struct Biotechnol J. 2018;16:211-23.

7. Dillon SC, Zhang X, Trievel RC, Cheng X. The SET-domain protein superfamily: protein lysine methyltransferases. Genome Biol. 2005;6:227. https ://doi.org/10.1186/gb-2005-6-8-227.

8. van Leeuwen F, Gafken PR, Gottschling DE. Dot1p modulates silencing in yeast by methylation of the nucleosome core. Cell. 2002;109:745-56.

9. Metzger E, Wang S, Urban S, Willmann D, Schmidt A, Offermann A, et al. KMT9 monomethylates histone $\mathrm{H} 4$ lysine 12 and controls proliferation of prostate cancer cells. Nat Struct Mol Biol. 2019;26:361-71. https://doi. org/10.1038/s41594-019-0219-9.

10. Figaro S, Scrima N, Buckingham RH, Heurgué-Hamard V. HemK2 protein, encoded on human chromosome 21, methylates translation termination factor eRF1. FEBS Lett. 2008;582:2352-6. https://doi.org/10.1016/j.febs| et.2008.05.045.

11. Lynch TJ, Bell DW, Sordella R, Gurubhagavatula S, Okimoto RA, Brannigan $\mathrm{BW}$, et al. Activating mutations in the epidermal growth factor receptor underlying responsiveness of non-small-cell lung cancer to gefitinib. N Engl J Med. 2004;350:2129-39. https://doi.org/10.1056/NEJMoa040938.

12. Liu P, Nie S, Li B, Yang Z-Q, Xu Z-M, Fei J, et al. Deficiency in a glutaminespecific methyltransferase for release factor causes mouse embryonic lethality. Mol Cell Biol. 2010;30:4245-53.

13. Ratel D, Ravanat J-L, Charles M-P, Platet N, Breuillaud L, Lunardi J, et al. Undetectable levels of N6-methyl adenine in mouse DNA: cloning 
and analysis of PRED28, a gene coding for a putative mammalian DNA adenine methyltransferase. FEBS Lett. 2006;580(13):3179-84.

14. Burnette WN. "Western Blotting": electrophoretic transfer of proteins from sodium dodecyl sulfate-polyacrylamide gels to unmodified nitrocellulose and radiographic detection with antibody and radioiodinated protein A. Anal Biochem. 1981;112:195-203.

15. Suzuki K, Bose P, Leong-Quong RYY, Fujita DJ, Riabowol K. REAP: a two minute cell fractionation method. BMC Res Notes. 2010;3:294.

16. Roth V. 2006 doubling time computing. http://www.doubling-time.com/ compute.php. Accessed 4 Sept 2018.

17. Dobin A, Davis CA, Schlesinger F, Drenkow J, Zaleski C, Jha S, et al. STAR: ultrafast universal RNA-seq aligner. Bioinformatics. 2013;29:15-21. https:// doi.org/10.1093/bioinformatics/bts635.

18. Robinson MD, Smyth GK. Small-sample estimation of negative binomial dispersion, with applications to SAGE data. Biostatistics. 2008;9:321-32. https://doi.org/10.1093/biostatistics/kxm030

19. Subramanian A, Tamayo P, Mootha VK, Mukherjee S, Ebert BL, Gillette MA, et al. Gene set enrichment analysis: a knowledge-based approach for interpreting genome-wide expression profiles. Proc Natl Acad Sci. 2005:102:15545

20. Mootha VK, Lindgren CM, Eriksson K-F, Subramanian A, Sihag S, Lehar J, et al. PGC-1a-responsive genes involved in oxidative phosphorylation are coordinately downregulated in human diabetes. Nat Genet. 2003;34:267. https://doi.org/10.1038/ng1180.

21. Gene set enrichment analysis. http://software.broadinstitute.org/gsea/ index.jsp. Accessed 26 Sept 2018.

22. Föll MC, Fahrner M, Oria VO, Kühs M, Biniossek ML, Werner M, et al. Reproducible proteomics sample preparation for single FFPE tissue slices using acid-labile surfactant and direct trypsinization. Clin Proteom. 2018:15:11.

23. Yu Y-Q, Gilar M, Lee PJ, Bouvier ESP, Gebler JC. Enzyme-friendly, mass spectrometry-compatible surfactant for in-solution enzymatic digestion of proteins. Anal Chem. 2003;75:6023-8. https://doi.org/10.1021/ac034 6196.

24. Kulak NA, Pichler G, Paron I, Nagaraj N, Mann M. Minimal, encapsulated proteomic-sample processing applied to copy-number estimation in eukaryotic cells. Nat Methods. 2014;11:319. https://doi.org/10.1038/ nmeth.2834.

25. Mueller S, Wahlander A, Selevsek N, Otto C, Ngwa EM, Poljak K, et al. Protein degradation corrects for imbalanced subunit stoichiometry in OST complex assembly. Mol Biol Cell. 2015;26:2596-608.

26. Thompson A, Schäfer J, Kuhn K, Kienle S, Schwarz J, Schmidt G, et al. Tandem mass tags: a novel quantification strategy for comparative analysis of complex protein mixtures by MS/MS. Anal Chem. 2003;75:1895-904. https://doi.org/10.1021/ac0262560.

27. Deutsch EW, Csordas A, Sun Z, Jarnuczak A, Perez-Riverol Y, Ternent T, et al. The ProteomeXchange consortium in 2017: supporting the cultural change in proteomics public data deposition. Nucleic Acids Res. 2017;45:D1100-6.
28. Perez-Riverol Y, Csordas A, Bai J, Bernal-Llinares M, Hewapathirana S, Kundu DJ, et al. The PRIDE database and related tools and resources in 2019: improving support for quantification data. Nucleic Acids Res. 2019:47:D442-50

29. Chandrashekar DS, Bashel B, Balasubramanya SAH, Creighton CJ, PonceRodriguez I, Chakravarthi BVSK, et al. UALCAN: a portal for facilitating tumor subgroup gene expression and survival analyses. Neoplasia. 2017;19:649-58.

30. Goswami CP, Nakshatri H. PROGgeneV2: enhancements on the existing database. BMC Cancer. 2014;14:970. https://doi. org/10.1186/1471-2407-14-970.

31. PROGgeneV2 — pan cancer prognostics database. http://genomics.jeffe rson.edu/proggene/index.php. Accessed 24 Aug 2018.

32. Wilkerson MD, Yin X, Walter V, Zhao N, Cabanski CR, Hayward MC, et al. Differential pathogenesis of lung adenocarcinoma subtypes involving sequence mutations, copy number, chromosomal instability, and methylation. PLoS ONE. 2012;7:e36530.

33. Blanco R, Iwakawa R, Tang M, Kohno T, Angulo B, Pio R, et al. A gene-alteration profile of human lung cancer cell lines. Hum Mutat. 2009:30:1199-206.

34. Berghe TV, Linkermann A, Jouan-Lanhouet S, Walczak H, Vandenabeele P. Regulated necrosis: the expanding network of non-apoptotic cell death pathways. Nat Rev Mol Cell Biol. 2014;15:135-47. https://doi.org/10.1038/ nrm3737.

35. Li X, Zhao Q, Wei W, Lin Q, Magnan C, Emami MR, et al. The DNA modification N6-methyl-2'-deoxyadenosine (m6dA) drives activity-induced gene expression and is required for fear extinction. Nat Neurosci. 2019;22:53444. https://doi.org/10.1038/s41593-019-0339-x.

36. Paez JG, Jänne PA, Lee JC, Tracy S, Greulich H, Gabriel S, et al. Mutations in lung cancer: correlation with clinical response to gefitinib therapy. Science (80-). 2004:304:1497-500

37. Pao W, Miller VA, Kris MG. 'Targeting'the epidermal growth factor receptor tyrosine kinase with gefitinib (Iressa ${ }^{\circledR}$ ) in non-small cell lung cancer (NSCLC). Semin Cancer Biol. 2004;14:33-40.

38. Breuer RH, Snijders PJ, Smit EF, Sutedja TG, Sewalt RG, Otte AP, et al. Increased expression of the EZH2 polycomb group gene in BMI1-positive neoplastic cells during bronchial carcinogenesis. Neoplasia. 2004;6:736-43

39. Shi Y, Lan F, Matson C, Mulligan P, Whetstine JR, Cole PA, et al. Histone demethylation mediated by the nuclear amine oxidase homolog LSD1. Cell. 2004;119:941-53.

\section{Publisher's Note}

Springer Nature remains neutral with regard to jurisdictional claims in published maps and institutional affiliations.
Ready to submit your research? Choose BMC and benefit from:

- fast, convenient online submission

- thorough peer review by experienced researchers in your field

- rapid publication on acceptance

- support for research data, including large and complex data types

- gold Open Access which fosters wider collaboration and increased citations

- maximum visibility for your research: over 100M website views per year

At BMC, research is always in progress.

Learn more biomedcentral.com/submissions 